\title{
Induced Effects of Environmentally Friendly Generations in Korea
}

\author{
Ji-Whan Kim ${ }^{1}$ and Yoon-Kyung Kim ${ }^{2, * \mathbb{D}}$ \\ 1 Northern Geoscience \& Mineral Resources Strategy Center, Korea Institute of Geoscience and Mineral \\ Resources, Daejeon 34132, Korea; kjiwhan@kigam.re.kr \\ 2 Department of Economics, Ewha Womans University, Seoul 03760, Korea \\ * Correspondence: yoonkkim@ewha.ac.kr; Tel.: +82-3277-4690
}

check for

updates

Citation: Kim, J.-W.; Kim, Y.-K. Induced Effects of Environmentally Friendly Generations in Korea. Sustainability 2021, 13, 4404. https:// doi.org/10.3390/su13084404

Academic Editor: Bacenetti Jacopo

Received: 24 February 2021

Accepted: 13 April 2021

Published: 15 April 2021

Publisher's Note: MDPI stays neutral with regard to jurisdictional claims in published maps and institutional affiliations.

Copyright: (C) 2021 by the authors. Licensee MDPI, Basel, Switzerland. This article is an open access article distributed under the terms and conditions of the Creative Commons Attribution (CC BY) license (https:// creativecommons.org/licenses/by/ $4.0 /)$.

\begin{abstract}
This study estimated the induced effects of LNG, mega PV (photovoltaic), small PV, onshore wind and offshore wind power, which will be used as major power sources under the Korea's energy transition policy. The 2015 Input-Output Statistics of Bank of Korea were used to reflect Korea's economic structure. The MCI (manufacture, construction and installation) and O\&M (operation and maintenance) of each power source would have different effects, so in the analysis the MCI and O\&M of each power source were distinguished. According to estimation results, the induced-effect coefficients of the MCI are greater than those of the O\&M in every power source. The induced production effect coefficient of the MCI is decreased in the order of mega PV > small PV $>$ LNG power $>$ offshore wind $>$ onshore wind. The induced production effect coefficient of the O\&M is decreased in the order of mega PV $>$ small PV $>$ onshore wind $>$ offshore wind $>$ LNG thermal. The induced employment coefficient of the MCI is decreased in the order of LNG thermal > mega PV > small PV > onshore wind > offshore wind. PV power and wind power have bigger induced effects and bring economic effects in Korean economy. The carbon neutrality and energy transition policies implemented by Korea have a certain level of induced effects and offset the burden of transition costs even if existing power sources are replaced with environmentally friendly power sources.
\end{abstract}

Keywords: induced effect; energy transition; renewable energy; Input-Output statistics

\section{Introduction}

Since the early 2010s, EU nations such as Germany, the UK, France, etc. and Japan have implemented policies to shift fossil fuel energy-based energy systems to renewable energy-based energy systems to cope with climate change. In the past few decades, only a few countries have pushed for a national energy transition, which has been slow. Recently, however, the energy transition policy has expanded to many countries and is progressing rapidly [1]. According to IRENA's Transforming Energy Scenario with Deep Decarbonization Perspective, energy transition realizes a sustainable low-carbon society, increases employment, further promotes economic growth and cleanses living conditions [2].

The Korean government confirmed the energy transition policy as a national task, and established the Energy Conversion Roadmap, Renewable Energy 3020, the eighth Electricity Supply-Demand Basic Plan in 2017 (hereafter the eighth basic plan), and the third Energy Basic Plan in 2019. In December 2020, the government announced its 2050 Carbon Neutral Vision. Korea's energy transition is to transform itself into a safe and clean future energy system centered on renewable energy and energy efficiency in response to climate change, fine dust reduction, and the safety of nuclear power [3].

The Korean government implements energy transition policies that tend to phase out nuclear power and coal power [4-6]. The Renewable Energy 3020 plan has been established to increase the share of renewable generation to $20 \%$ by 2030 . The eighth basic plan includes an environmentally friendly generation mix [5]. In the third Energy Basic Plan, the midto long-term policy direction of energy transition has been established and the renewable 
energy share target by 2040 was expanded to be around 30 to 35\% [7]. As renewable energy sources become more competitive both technologically and economically, renewable energy is increasing its share not only in Korea but also in many other countries. By 2040, the renewable energy share in OECD countries will increase to 42\% [6,7].

As the energy transition policy changes the generation mix, the required inputs will also be changed. Additionally, the inputs are different for each generation source in each step of construction and operation. The change in the inputs required affects the production activities of the industrial sectors, industrial structure, product composition, and employment level of the country. The structural impact of energy transition and the impact on the labor market will vary depending on the region, industry and working contract type [2].

According to the analysis results of the Mitsubishi Research Institute (MRI) [8], in the case of photovoltaic (hereafter PV) power and wind power, the construction stage has a ripple effect that is greater than the operation stage, regardless of scale. In the view of PV power by scale, during the construction phase of the facility, the effect of mega PV is greater than that of single-house PV. This is because mega PV includes land groundwork [8]. Matsumoto and Hondo [9] described that in the case of single-house PV-generation, the production of facilities manufacturing, operation, and maintenance is large, but the employment coefficient is small, so the effect of job creation is not significant. Matsumoto and Hondo [9] estimated that the production and employment of wind power operations and repairs are greater than in other forms of renewable energy.

According to the International Renewable Energy Agency (IRENA)'s research on estimating the employment effect of renewable energy, induced employment increased in China, Brazil, the US, India, Japan, and Germany [10]. Using Input-Output analysis, Baba [11] analyzed that the induced employment effect of solar and wind power is greater than conventional power generation (thermal, nuclear, hydro) in both generation (people/Million kWh) and capacity (people/thousand kW) [11]. Mah and Cheung [12] presented Seoul's urban PV power along with London and New York as examples of continuous lower costs of PV facilities and greater success for policymakers in finding more cost-effective energy policies.

Each country's socioeconomic situation varies depending on domestic natural resources such as fossil fuels and other primary products, industrial productivity, technology options, and the depth and diversity of the domestic supply chain. It has a positive effect when policy customized to a specific country is implemented. This is also the same in energy transition policy.

Generation mix will be changed when a country places importance on the environmental friendliness and safety of the generation source in energy policy unlike before and implements energy transition policy. This changes goods and services in the national economy, production activities and labor demand of each industrial sector. Nuclear power and coal power, which Korea has mainly used in generation, had a large capacity and generation, large-scale construction and facility costs, and operation costs corresponding to its generation. Renewable energy sources, which are increasing in the energy transition policy, have small capacity and generation. These power sources consist of different facilities. As the power sources with different characteristics increase, Korea's economic structure changes accordingly. Even if the energy sources increasing in the energy transition policy have an environmental advantage, they may not induce production in other industries. Therefore, this study estimates the induced effects of environmentally friendly power sources in the energy transition policy and measures the effect of these power sources on the national economy.

This study assumes the representative capacity and generation of power sources that will continue to increase in Korea, which promotes energy transition policy. This study also estimates the induced effect of these generation sources on the Korean economy when they are manufactured, constructed, installed, operated and maintained. The analysis covers five capacities of three generation sources. Those are LNG thermal power, $900 \mathrm{MW}$; 
small photovoltaic power (hereafter small PV), $3 \mathrm{~kW}$; mega photovoltaic power (hereafter Mega PV), $100 \mathrm{~kW}$; onshore wind power, $10 \mathrm{MW}$; and offshore wind power, $120 \mathrm{MW}$. The phase of manufacturing power facilities, building power plants, and installing facilities in the plant is called manufacture, construction and installation (hereafter MCI). The phase of operating a power plant and performing various maintenance is called operation and maintenance (hereafter O\&M). The analysis method is the Input-Output model (hereafter the IO model), and the induced production effect, the induced value-added effect, and the induced employment effect are estimated.

Accordingly, the analysis reflects Korea's economic, production and consumption structure using Korea's 2015 Input-Output Statistics (benchmark) published in 2019 [13] (statistics such as sales, generation, facility capacity, capacity factor, employee, performance by power company, electricity transaction amounts in the electricity industry sector use the values of 2015). The Input-Output table (hereafter the IO table) for this analysis is made by separating LNG thermal power, small PV power, mega PV power, onshore wind power, and offshore wind power in the 2015 Input-Output Statistics. The MCI and O\&M of each generation source are separately reflected. The MCI cost and O\&M cost required to include the generation sources to 2015 Input-Output Statistics are cited in the eighth basic plan (the electricity supply-demand basic plan is established every two years pursuant to Article 25 of the Electricity Business Act and Article 15 of the Enforcement Decree in order to forecast mid- to long-term electricity demand and to expand electricity facilities accordingly. Korea has established the electricity supply-demand basic plan since 2002. The eighth electricity supply-demand basic plan, published in 2017, covers 2017 2031. The ninth electricity supply-demand basic plan has yet to be announced, and it went through the process of a public hearing at the end of 2019. Therefore, the latest official electricity supply-demand basic plan is the 8th basic plan). The estimated cost of KEEI [14] is also applied to the MCI cost and O\&M cost of PV power and wind power. The share for the allocation of the IO table by industry sector is referred to in the related literature.

This paper consists of the following: Section 2 describes the IO model and the InputOutput matrix balance method. The matrix balance method is applied when expanding the IO table for the analysis and balancing matrix. Section 3 prepares an IO table for empirical analysis by separating the MCI and O\&M of LNG thermal power, mega PV power, small PV power, onshore wind power and offshore wind power. Furthermore, the input and distribution structure of each power source are investigated. Section 4 presents the empirical analysis results of the induced production effects, induced value-added effects, and induced employment effects of LNG thermal power, mega PV power, small $P V$ power, onshore wind power and offshore wind power. Section 5 is the discussion. The empirical results are compared with the results of previous studies. The parts that were not considered in this analysis are also mentioned. Section 6 is the conclusion.

\section{Analysis Methods}

\subsection{The Input-Output Model}

The analysis is performed using the IO table and IO model. The IO table is consistent with National Income Accounts and other statistics [15]. This table contains all the transactions related to economic activities that typically represent the production and allocation of goods and services by industry over a one-year period.

Equation (1) is an expression of the IO table. According to the National Income Accounts, a country's gross output is the sum of production by final demand and production by export minus production by import. In the matrix expressing transactions between industries, the direct required matrix $(A)$ is the direct input requirement for one unit of output. Matrix $(A)$ is derived from the transaction matrix calculated by dividing the input by the total output of each industry. The interdependence coefficients, which consist of the Leontief inverse matrix $(I-A)^{-1}$, indicate the direct and indirect changes in the economy needed to meet the one unit imposed on the final demand (the Leontief inverse matrix (interdependence coefficient) is derived by subtracting the unit matrix $(I)$ of the same 
size from the direct input coefficient matrix $(A)$ to obtain the $(I-A)$ matrix and the $(I-A)$ in reverse). This is the result of changes in the final demand and is used to estimate changes in the output. In $(I-A)^{-1}$, each component $\left(b_{i j}\right)$ of the Leontief inverse matrix is the output of the direct and indirect required from industry $i$ for one unit of final demand imposed on industry $j$. The total change made from the change in one unit of the final demand for the output of the industry $j$ is a summation of row $\left(\sum_{j} b_{i j}\right)$.

$$
\begin{gathered}
X=X_{F D}+X_{E X}-X_{I M}, \\
X=(I-A)^{-1}(F D+E X-I M), \\
V A=V(I-A)^{-1}(F D+E X-I M), \\
U=L(I-A)^{-1}(F D+E X-I M),
\end{gathered}
$$

$$
\begin{gathered}
X=\left(\begin{array}{c}
X_{1} \\
\vdots \\
X_{n}
\end{array}\right), F D=\left(\begin{array}{c}
F D_{1} \\
\vdots \\
F D_{n}
\end{array}\right), E X=\left(\begin{array}{c}
E X_{1} \\
\vdots \\
E X_{n}
\end{array}\right), I M=\left(\begin{array}{c}
I M_{1} \\
\vdots \\
I M_{n}
\end{array}\right), V=\left(\begin{array}{c}
V_{1} \\
\vdots \\
V_{n}
\end{array}\right), L=\left(\begin{array}{c}
L_{1} \\
\vdots \\
L_{n}
\end{array}\right), \\
A=\left(\begin{array}{ccc}
a_{11} & \cdots & a_{i N} \\
\vdots & \ddots & \vdots \\
a_{N 1} & \cdots & a_{N N}
\end{array}\right),(I-A)^{-1}=\left(\begin{array}{ccc}
b_{11} & \cdots & b_{i N} \\
\vdots & \ddots & \vdots \\
b_{N 1} & \cdots & b_{N N}
\end{array}\right), a_{i j}=\frac{x_{i j}}{X_{j}}, V_{i}=\frac{v_{j}}{X_{j}}, L_{j}=\frac{l_{j}}{X_{j}}
\end{gathered}
$$$$
i, j=1, \ldots, N \text {. }
$$

$F D$
$E X$
$I M$
$V$
$L$
$X_{F D}$
$X_{E X}$
$X_{I M}$
$X_{j}$
$x_{i j}$
$V_{j}$
$l_{j}$
$I$
$(I-A)^{-1}$

final demand vector
export vector
import vector
value-added rate vector
employment coefficient vector
induced output by final demand
induced output by export
induced output by import
total output of industry $j$
input from industry $i$ to industry $j$
total value-added of industry $j$
employment coefficient of industry $j$
unit matrix
Leontief inverse matrix

The induced-effect analysis assumes the stability of the input coefficient and import coefficient, and estimates the output induced directly and indirectly in the production and consumption of each industry to meet the given one unit in the final demand. The inducedeffect analysis uses the Leontief inverse matrix based on the input coefficient matrix $(A)$. The induced production and induced value-added are as shown in Equations (2) and (3), respectively. These express the effect on the production and value-added of each industry directly and indirectly when the final demand of a certain industry increases by one unit. The induced employment is as shown in Equation (4) and expresses the number of employees directly and indirectly induced in each industry when the final demand of a certain industry by increases one unit.

\subsection{Input-Output Matrix Balance Method}

In this study, target generation sources are added to the 2015 Input-Output Statistics and thus the balance should be maintained between the total input and total output of the IO table. The matrix balance method estimates the sum of each sector's output using the relevant data and estimates the input coefficients at the forecast time based on the 
input coefficients at the benchmark year. This method is used when provisional values related to, for example, the sum of intermediate inputs, sum of intermediate demands, or productions, are identified (when estimating an undated Input-Output table, there is a data availability problem due to time constraints from preparation to publication. The final stage of the estimation uses a matrix balance method). The Bank of Korea uses the matrix balance method in the extended table prepared to supplement the benchmark InputOutput Statistics published every five years [15]. The matrix balance method includes the RAS method, the mean average deviation method, and the Lagrangian multiplier method. (The RAS method and the mean average deviation method are based on the iterative calculation. The Lagrangian multiplier method is based on the statistical method.)

In this study, the Lagrangian multiplier method is used to balance the Input-Output Table. The Lagrangian multiplier method is simpler than the RAS method, and solves the problem that when using the RAS method, the estimated input coefficient matrix does not converge to the information of the forecast time. The Lagrangian multiplier method is a least-squared method that minimizes the sum of the squared differences between the input coefficient at the base time and the input coefficient at the forecast time, under the conditions that the sum of rows and sum of columns are equal with provisional intermediate demand and provisional intermediate input, respectively, in each industry [16]. Equations of the Lagrangian multiplier method are as follows [16,17]. This is a problem that minimizes the objective function as Equation (5) under constraints as Equation (6) and Equation (7). The weights $\left(w_{C_{i j}}\right.$, $\left.w_{R_{i j}}\right)$ used in Equation (5) are 1, $1 / a_{C_{i j}}, 1 / a_{R_{i j}}$, and so on, and the appropriate weights are chosen according to the analysis motivation. Equation (5) is solved by the Lagrangian function.

$$
\begin{gathered}
\min \frac{1}{2} \sum_{i=1}^{N} \sum_{j=1}^{M}\left\{w_{C_{i j}}\left(\frac{x_{i j}}{X_{C_{j}}}-a_{C_{i j}}\right)^{2}\right\}+\frac{1}{2} \sum_{i=1}^{N} \sum_{j=1}^{M}\left\{w_{R_{i j}}\left(\frac{x_{i j}}{X_{R_{i}}}-a_{R_{i j}}\right)^{2}\right\}, \\
\text { s.t. } \sum_{j=1}^{M} x_{i j}=X_{R_{i}} \\
\sum_{i=1}^{N} x_{i j}=X_{C_{j}}
\end{gathered}
$$

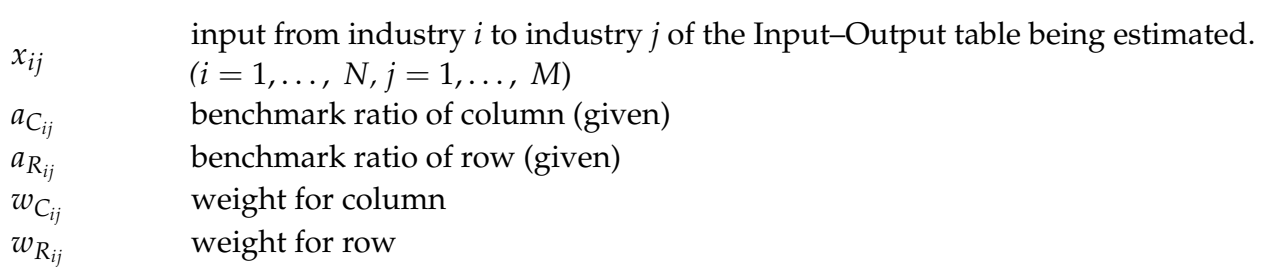

With the base time 0 and the forecast time $t$, the Lagrangian multiplier method is based on the input coefficient $a_{C_{i j}}^{0}\left(=\frac{x_{i j}^{0}}{X_{C_{j}}^{0}}\right)$, the output ratio $a_{R_{i j}}^{0}\left(=\frac{x_{i j}^{0}}{X_{R_{j}}^{0}}\right)$, the column ratio $\left(\frac{v_{i j}^{0}}{X_{C_{j}}^{0}}\right)$ and row ratio $\left(\frac{v_{i j}^{0}}{V_{i}^{0}}\right)$ of value-added, and the column ratio $\left(\frac{f_{i j}^{0}}{F_{j}^{0}}\right)$ and row ratio $\left(\frac{f_{i j}^{0}}{X_{R_{i}}^{0}}\right)$ of final demand. The objective function as Equation (8) is minimized subject to the constraints as Equations (9)-(12), given the production of row $i\left(X_{R_{i}}^{t}\right)$, the production of column $j\left(X_{C_{j}}^{t}\right)$, the sum of value-added by sector $\left(V_{i}^{t}\right)$, and the sum of final demand by sector $\left(F_{j}^{t}\right)$ at the forecast time. This gives the value of $x_{i j}^{t}, f_{i j}^{t}, v_{i j}^{t}$ of the Input-Output Table at the forecast time. When applying the Lagrangian multiplier method, KEO-RAS method choices $1 / a_{C_{i j}}^{2}$ and $1 / a_{R_{i j}}^{2}$ as weights for column and row, respectively. 


$$
\begin{gathered}
\min \mathrm{Q}=\frac{1}{2} \sum_{i=1}^{N} \sum_{j=1}^{M}\left(\frac{x_{i j}^{t} / X_{C_{j}}^{t}}{a_{C_{i j}}^{0}}-1\right)^{2}+\frac{1}{2} \sum_{i=1}^{K} \sum_{j=1}^{M}\left(\frac{v_{i j}^{t} / X_{C_{j}}^{t}}{v_{i j}^{0} / X_{C_{j}}^{0}}-1\right)^{2} \\
+\frac{1}{2} \sum_{i=1}^{N} \sum_{j=1}^{L}\left(\frac{f_{i j}^{t} / F_{j}^{t}}{f_{i j}^{0} / F_{j}^{0}}-1\right)^{2}+\frac{1}{2} \sum_{i=1}^{N} \sum_{j=1}^{M}\left(\frac{x_{i j}^{t} / X_{R_{i}}^{t}}{a_{R_{i j}}^{t}}-1\right)^{2}+\frac{1}{2} \sum_{i=1}^{N} \sum_{j=1}^{L}\left(\frac{f_{i j}^{t} / X_{R_{i}}^{t}}{f_{i j}^{0} / X_{R_{i}}^{0}}-1\right)^{2} \\
\text { s.t. } \sum_{i=1}^{N} x_{i j}^{t}+\sum_{i=1}^{K} v_{i j}^{t}=X_{C_{j}}^{t}(j=1, \ldots, M) \\
\sum_{i=1}^{N} f_{i j}^{t}=F_{j}^{t},(j=1, \ldots, L) \\
\sum_{j=1}^{M} x_{i j}^{t}+\sum_{j=1}^{L} f_{i j}^{t}=X_{R_{i}}^{t},(i=1, \ldots, N) \\
\sum_{j=1}^{M} v_{i j}^{t}=V_{i}^{t},(i=1, \ldots, K)
\end{gathered}
$$

$$
\begin{aligned}
& x_{i j}^{t} \\
& v_{i j}^{t} \\
& f_{i j}^{t} \\
& \sum_{j=1}^{M} x_{i j}^{t}+\sum_{j=1}^{L} f_{i j}^{t}=X_{R_{i}}^{t} \\
& \sum_{i=1}^{N} x_{i j}^{t}+\sum_{i=1}^{K} v_{i j}^{t}=X_{C_{j}}^{t} \\
& \sum_{j=1}^{M} v_{i j}^{t}=V_{i}^{t} \\
& \sum_{i=1}^{N} f_{i j}^{t}=F_{j}^{t}
\end{aligned}
$$

input from industry $i$ to industry $j$ at time $t$ $(i=1, \ldots, N, j=1, \ldots, M)$ input from value-added sector $i$ to industry $j$ at time $t$ $(i=1, \ldots, K, j=1, \ldots, M)$ demand of final demand sector $j$ to industry $i$ at time $t$ $(i=1, \ldots, N, j=1, \ldots, L)$ total output of industry $i$ (row) $(i=1, \ldots, N)$ total input of industry $j$ (column) $(j=1, \ldots, M)$ Total value-added of value-added sector $i(i=1, \ldots, K)$ Total final demand of final demand sector $j(j=1, \ldots, L)$

\section{Statistics for the Input-Output Table with Analysis Target Generation Sources}

\subsection{The Input and Output Structure of LNG Thermal, Photovoltaic and Wind Power}

The construction cost of LNG thermal power is referred to in the total cost of the eighth basic plan. The construction cost consists of the direct cost, indirect cost, and construction interest, while the indirect costs consist of design service costs, land costs, owner's cost, foreign capital manufacture cost, and reserve funds. According to the eighth basic plan, the construction cost of $900 \mathrm{MW}$ LNG power is $851,000 \mathrm{won} / \mathrm{kW}$, and the net construction cost excluding construction interest is $814,000 \mathrm{won} / \mathrm{kW}$. The standard construction period for LNG power (450 MW and $900 \mathrm{MW}$ ) is 28 months.

The intermediate input share $(53.08 \%)$ and the value-added share $(46.92 \%)$ of the power plant (No.5133) in the base classification of the 2015 Input-Output Statistics are applied to the construction cost of LNG power plants. The intermediate input amount is allocated using the classification and cost share of LNG combined thermal power generation project in the KEPCO Management Research Institute [18]. The value-added amount is allocated using the sectoral share of the power plant (No.5133).

According to the eighth basic plan, the O\&M cost of 900MW LNG power is 2.77 won $/ \mathrm{kW} /$ month. The O\&M costs consist of labor costs $(38.1 \%)$, repair maintenance costs $(21.2 \%)$, expenses $(19.8 \%)$, general management costs $(16.2 \%)$, and others $(4.7 \%)$. The O\&M cost of the eighth basic plan is considered as a ceiling value when allocating the O\&M costs by component. The input and output structures for the O\&M of LNG thermal power cannot be obtained from the 2015 Input-Output Statistics. No.4502 thermal power of the basic-sized classification of the 2015 Input-Output Statistics is a sum of coal power, LNG power, and other thermal power, with one input structure and one distribution structure. LNG power is separated from the thermal power in the 2015 Input-Output Statistics to obtain the input structure. The composition of the input factors are adjusted. Since electricity produced from each generation source is not distributed separately, the distribution structure of LNG power follows the distribution structure of No. 45 electricity and the renewable energy sector of the medium-sized classification of 2015 Input-Output Statistics. 
The construction costs and O\&M costs of PV power and wind power are referred to by the KEEI [14]. As shown in Table 1, these data consist of the Capital Expenses (hereafter CAPEX), O\&M, insurance, and corporate taxes. The sector shares of CAPEX and O\&M for $\mathrm{PV}$ power and wind power are required to link them to the classification in the IO table. The sector shares are referred to by Mitsubishi Research Institute (MRI) [19,20], Nakamura, Ishikawa and Matsumoto [21], Science and Technology Foresight Center National Institute of Science and Technology Policy (NISTEP) Ministry of Education, Culture, Sports, Science and Technology Japan (MEXT) [22].

Table 1. Cost of photovoltaic power and wind power by scale.

\begin{tabular}{|c|c|c|c|c|c|c|c|}
\hline $\begin{array}{l}\text { Power } \\
\text { Source }\end{array}$ & Scale & $\begin{array}{c}\text { CAPEX } \\
\text { (Billion } \\
\text { Won/MW) }\end{array}$ & $\begin{array}{c}\text { O\&M } \\
\text { (Million } \\
\text { Won/MW/year) }\end{array}$ & $\begin{array}{c}\text { Insurance } \\
\text { (Million } \\
\text { Won/MW/year) }\end{array}$ & $\begin{array}{c}\text { Corporate } \\
\text { Tax (\%) }\end{array}$ & $\begin{array}{c}\text { Capacity } \\
\text { Factor }(\%)\end{array}$ & $\begin{array}{l}\text { Life Time } \\
\text { (year) }\end{array}$ \\
\hline \multirow{2}{*}{ PV } & $\begin{array}{c}\text { Mega } \\
(100 \mathrm{~kW})\end{array}$ & 0.14 & 16.0 & 14.0 & 24.2 & 14.75 & 20 \\
\hline & $\begin{array}{c}\text { Small } \\
(3 \mathrm{~kW})\end{array}$ & 0.16 & 17.6 & 15.4 & 12.1 & 14.75 & 20 \\
\hline \multirow{2}{*}{ Wind } & $\begin{array}{c}\text { Onshore } \\
\text { (10 MW Farm, } \\
2 \text { MW Turbine) }\end{array}$ & 2.5 & 30.0 & 17.5 & 24.2 & 23 & 20 \\
\hline & $\begin{array}{c}\text { Offshore } \\
\text { (120 MW Farm, } \\
5 \text { MW Turbine) }\end{array}$ & 5.0 & 172.1 & 38.5 & 24.2 & 30 & 20 \\
\hline
\end{tabular}

CAPEX is capital expenses. Source: KEEI, 2017.

In Japan, the share of intermediate inputs and value-added for house PV generation is $74.6 \%$ and $25.3 \%$, respectively, in construction and $7.2 \%$ and $92.8 \%$, respectively, in operation [19]. The share of intermediate inputs and value-added for non-house PV generation is $75.9 \%$ and $24.1 \%$, respectively, in construction and $10.2 \%$ and $89.8 \%$, respectively, in operation. The ratio of intermediate inputs and value-added for mega PV generation is $73.5 \%$ and $26.5 \%$, respectively, in construction and $4.6 \%$ and $95.4 \%$, respectively, in operation [19]. PV generation, regardless of its size, has a large intermediate input and a small value-added in construction, and a very small intermediate input and a very large value-added in operation. The shares of non-house PV and mega PV are used to allocate the $\mathrm{MCI}$ cost and O\&M cost.

The cost of PV power depends on various factors such as technology, installation characteristics, system size, and supplier's price spread [23]. In PV power systems, the module's cost accounts for half of the installation cost, including mounting equipment, the power inverter, the electrical wing, connection equipment, location selection and permission, design, and installation services cost. According to the system cost of PV power, the largest one in capital cost (382.6 thousand yen $/ \mathrm{kW}$ ) is the installation cost $(76.9 \%)$, followed by the construction cost $(19.5 \%)$. In addition, there are access cost $(2.0 \%)$, land construction costs $(1.2 \%)$ and design costs $(0.4 \%)$ [19]. The sum of installation costs and construction costs is more than $95 \%$ of the total capital costs. In the O\&M cost by size, the labor cost excluding land rents is the largest and 2100 yen/ $/ \mathrm{kW} /$ year in $10 \sim 50 \mathrm{~kW}$. The next largest cost is the repair costs [19]. For $10 \sim 50 \mathrm{~kW}$, labor costs and repair costs account for $55 \%$ of the total O\&M costs [19].

In Japan, the share of intermediate inputs and value-added of wind power is $78.1 \%$ and $21.9 \%$, respectively, in construction and $15.7 \%$ and $84.3 \%$, respectively, in operation [19]. These shares are kept regardless of type and size. In the case of construction, the intermediate inputs are large and the value-added is small. The construction cost breakdown of onshore and offshore wind power is as shown in Table 2 [22]. In the case of the O\&M, the intermediate inputs are small and the value-added is large. 
Table 2. Construction cost of wind power (purchaser's price).

\begin{tabular}{cccc}
\hline \multicolumn{1}{c}{ Onshore Wind. } & \multicolumn{2}{c}{ Offshore Wind } \\
\hline Item & Share (\%) & Item & Share (\%) \\
\hline windmill body & 58.4 & wind power fertility & 43.7 \\
electrical equipment, etc. & 6.0 & electrical equipment & 10.7 \\
electrical work & 8.4 & electrical work & 7.1 \\
windmill delivery & 3.4 & delivery & 5.2 \\
assembly installation & 4.7 & installation & 7.3 \\
civil engineering & 13.5 & foundation structure & 21.8 \\
inquiry & 1.5 & developing, licensing & 3.1 \\
design & 1.3 & miscellaneous & 1.1 \\
start-up adjustment & 1.4 & & \\
electricity charges, etc. & 1.4 & &
\end{tabular}

The operating costs of wind power consist of a depreciation of $40 \%$, fixed asset tax and corporate tax of $15 \%$, maintenance cost of $10 \%$, insurance and financial cost of $10 \%$, land rent of $1 \%$, repair cost and general management cost of $5 \%$ and profit of $19 \%$ [22]. This, in turn, leads to capital depreciation, indirect taxes (excluding tariffs), construction maintenance, finance and insurance, real estate service and lease, employee's compensation and operating surplus of the IO table. The more recent the operation year, the smaller the operating cost [22]. The share of repair costs for those that started operating during $2001 \sim 2005$ is $57 \%$. The repair costs of wind power operated after the year 2006 decrease, with a share of $46 \%$.

Table 3 summarizes the facility capacity, capacity factor, generation, MCI cost, and the O\&M cost of the target generation sources. The MCI cost considers the facility capacity of each power sources. The O\&M cost considers the generation and capacity factor of each power source.

Table 3. Assumption for analysis target generation sources.

\begin{tabular}{cccccc}
\hline & $\begin{array}{c}\text { Capacity } \\
\text { (MW) }\end{array}$ & $\begin{array}{c}\text { Capacity Factor } \\
\text { (\%) }\end{array}$ & $\begin{array}{c}\text { Generation with } \\
\text { Capacity Factor } \\
\text { (MWh) }\end{array}$ & $\begin{array}{c}\text { MCI Cost } \\
\text { (Million Won) }\end{array}$ & $\begin{array}{c}\text { O\&M Cost } \\
\text { (Million Won) }\end{array}$ \\
\hline LNG Thermal & 900 & 42.9 & $3,382,236$ & 765,900 & 29,916 \\
Small PV & $0.003(3 \mathrm{~kW})$ & 14.8 & 4 & 4.500 & 0.099 \\
Mega PV & $0.100(100 \mathrm{~kW})$ & 14.8 & 129 & 25,148 & 3 \\
Onshore Wind & 10 & 23.0 & 315,360 & 600,000 & 475 \\
Offshore Wind & 120 & 30.0 & 25,272 \\
\hline
\end{tabular}

Capacity factors of LNG thermal and others are referred from capacity and generation by type data of EPSIS [24] and KEEI [14] respectively.

\subsection{Generation and Sales}

Facility capacity, generation and sales by generation source are referred in the 2015 Input-Output Statistics [13], 2015 Yearbook of Energy Statistics [25], and Statistics of Electric Power in Korea 2015 [26]. Table 4 shows the capacity and generation by source as of 2015 [25]. Table 5 shows the power trading and power turnover by energy source as of 2015 [25].

The induced-effect analysis uses these statistics compared to the statistics by power sources in the 2015 Input-Output Statistics. The total input in the electricity and renewable energy sector (No.45 in medium-sized classification) of the 2015 Input-Output Statistics is 59,575 billion won. Hydro (No.4501) is 89.1 billion won, thermal (No.4502) is 40,530 billion won, nuclear (No.4503) is 13,293 billion won, self-generation (No.4504) is 225.9 billion won, and renewable energy (No.4505) is 260.3 billion won (the number in parenthesis is the sector No. of base-sized classification of 2015 Input-Output Statistics). Since this study uses the 2015 Input-Output Statistics in the analysis, the total input of the 2015 
Input-Output Statistics is the control total (hereafter CT) and is distributed with the share of generation by the source above.

Table 4. Capacity and generation by source of 2015 .

\begin{tabular}{ccccccccc}
\hline & Nuclear & Coal & $\begin{array}{c}\text { LNG and } \\
\text { Combined Cycle }\end{array}$ & Hydro & Oil & $\begin{array}{c}\text { District } \\
\text { Energy }\end{array}$ & $\begin{array}{c}\text { Alternative } \\
\text { Energy }\end{array}$ & $\begin{array}{c}\text { Total } \\
\text { Capacity (MW) }\end{array}$ \\
Share & 21,716 & 26,274 & 28,900 & 6470 & 2950 & 5360 & 5649 & 97,649 \\
Generation (GWh) & $22.23 \%$ & $26.90 \%$ & $29.59 \%$ & $6.62 \%$ & $3.02 \%$ & $5.48 \%$ & $5.78 \%$ & $100.00 \%$ \\
Share & 164,762 & 207,334 & 100,820 & 5796 & 8822 & 22,019 & 17,318 & 528,091 \\
& $31.19 \%$ & $39.26 \%$ & $19.09 \%$ & $1.09 \%$ & $1.67 \%$ & $4.16 \%$ & $3.27 \%$ & $100.00 \%$ \\
\hline
\end{tabular}

Source: KEEI, 2016.

Table 5. Power trading and power turnover by source of 2015.

\begin{tabular}{|c|c|c|c|c|c|c|c|c|}
\hline & Nuclear & Coal & Oil & $\begin{array}{c}\text { LNG and } \\
\text { Combined Cycle }\end{array}$ & Hydro & Renewable & Others & Total \\
\hline Power Trading (GWh) & 157,196 & 201,070 & 9394 & 106,503 & 5152 & 15,810 & 264 & 495,390 \\
\hline Share & $31.73 \%$ & $40.59 \%$ & $1.90 \%$ & $21.50 \%$ & $1.04 \%$ & $3.19 \%$ & $0.05 \%$ & $100.00 \%$ \\
\hline Power Turnover (Billion won) & 9842 & 14,009 & 1408 & 13,450 & 663 & 1574 & 27 & 40,972 \\
\hline Share & $24.02 \%$ & $34.19 \%$ & $3.43 \%$ & $32.82 \%$ & $1.61 \%$ & $3.84 \%$ & $0.07 \%$ & $100.00 \%$ \\
\hline
\end{tabular}

\subsection{Employment}

The operational employee by power source is referred to in the 2015 Input-Output Statistics [13], 2015 Yearbook of Energy Statistics [25], Survey on the Status of Nuclear Industries in 2015 [27], and International Renewable Energy Agency (IRENA) [28]. According to the 2015 Input-Output Statistics, the number of people employed in electricity and renewable energy (No.45 in medium-sized classification) is 58,528 and the number of employees is 57,274 [13]. According to the Survey on the Status of Nuclear Industries in 2015, the number of nuclear power workers is 10,745 and the remaining 47,783 are employed by other generation sources [27]. The allocation of 47,783 workers using the proportion of facility capacity in the 2015 Yearbook of Energy Statistics was 12,854 for coal, 14,139 for gas, 3163 for hydro, 1443 for oil, 2618 for district energy and 2762 for alternative energy. The number of employed in the O\&M of LNG thermal is 0.48 people/MW.

The average employment of the OECD's manufacture, construction and installation (MCI) is 17.9 people/MW in PV power, 8.6 people/MW in onshore wind power, and 18.1 people/MW in offshore wind power [28]. The average employment of the OECD's O\&M is 0.3 people/MW people in PV power, and 0.2 people/MW in onshore and offshore wind power [28]. These OECD averaged are used as Korea's employment number in renewable energy.

\subsection{Composition of Input-Output Table with Analysis Target Generation Sources}

In the induced-effect analysis, the 2015 Input-Output Statistics (benchmark, producer's price) published in 2019 by the Bank of Korea was used [13]. To ensure that transactions among industries are explicitly revealed, the classification is maintained at medium size ( 83 sectors). The MCI sector and O\&M sector of LNG power (900 MW), small PV power $(3 \mathrm{~kW})$, mega PV power $(100 \mathrm{~kW})$, onshore wind power (10 MW), and offshore wind power $(120 \mathrm{MW})$ are added to the 2015 Input-Output Statistics. These are the No.84 LNG power MCI, No.85 LNG power O\&M, No.86 small PV power MCI, No.87 small PV power O\&M, No.88 Mega PV power MCI, No.89 Mega PV power O\&M, No.90 Onshore wind power MCI, No.91 onshore wind power O\&M, No.92 offshore wind power MCI, and No.93 offshore wind power O\&M. The total number of expanded classifications is 93 . The structure of the IO table with analysis target generation sources is shown in Figure 1. 


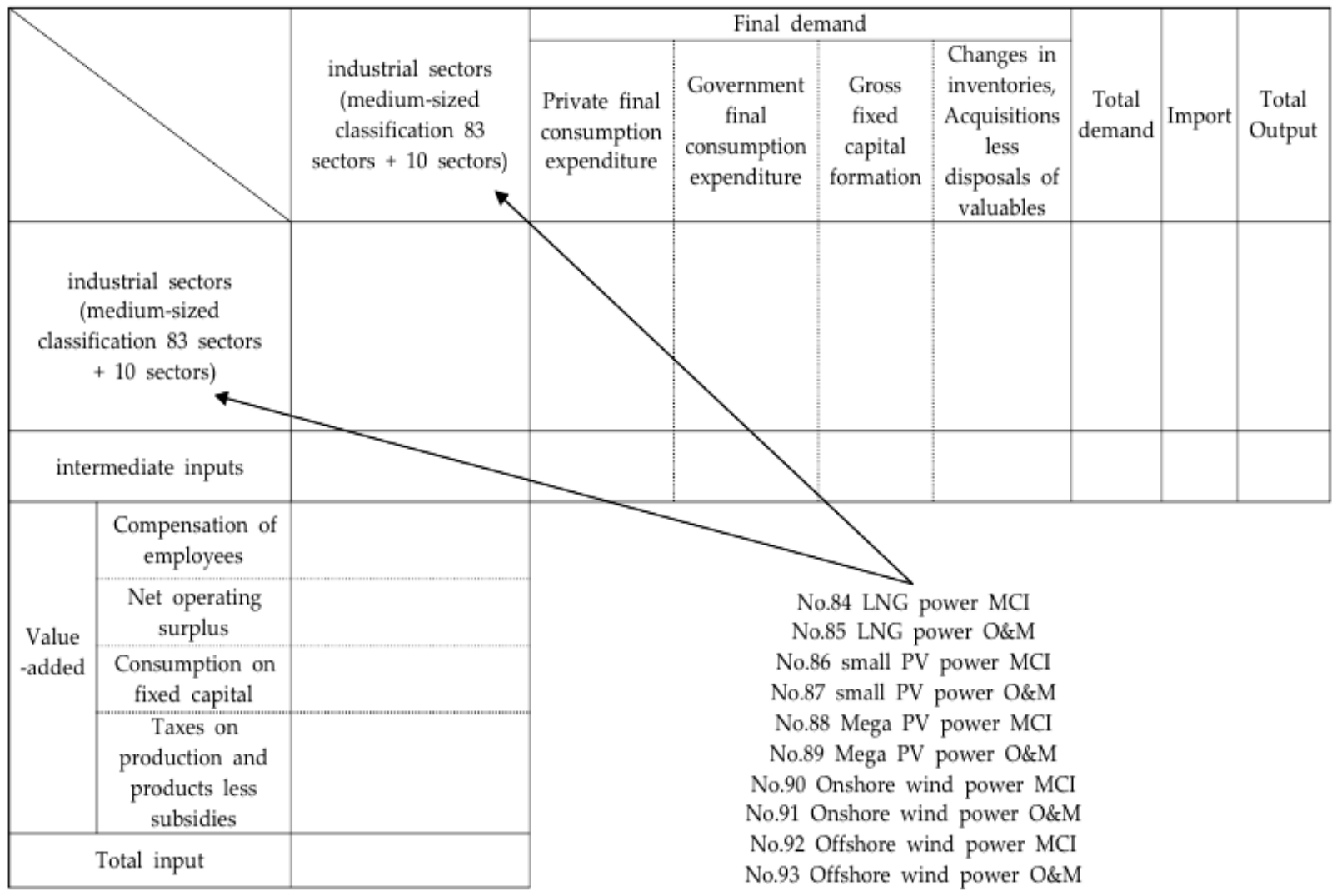

Figure 1. Input-Output table structure with analysis target generations.

The MCI period and O\&M period are one year each in the analysis. The construction of the $\mathrm{MCI}$ takes longer than a year and the construction cost expenses are not equal in each year. However, the analysis period is assumed to be one year because the IO table contains economic activity in a year. In addition, the induced-effect analysis uses the total cost of each project and the induced amount of this to derive the inducement coefficient. The induced-effect coefficient shows the direct and indirect effects induced by one unit of final demand for the power source, and thus excludes the influence of the amount of cost.

The outputs of the MCI are the power plant and facilities, and the output of the O\&M is electricity. The former is allocated to the fixed capital formation in the final demand and the latter is allocated according to the distribution share of the electricity and renewable energy sector (No.45 of basic-sized classification) from the 2015 Input-Output Statistics.

\section{Empirical Analysis}

\subsection{Backward Linkage Effect and forward Linkage Effect}

The backward linkage effect and forward linkage effect by generation source are shown in Table 6. The backward linkage effect is the total effect of the entire industries when the final demand for a certain industry increases by one unit. The forward linkage effect is the effect of a certain industry when the final demand for all the industries increases by one unit each. The average of the backward linkage effect of the entire industry is 1 . This is also the same for the forward linkage effect.

According to the backward linkage effect, the MCI has a greater value than the O\&M in all generation sources. The MCI has a lot of connections with other industries, which further affects other industries. The backward linkage effect of the MCI of mega PV power, onshore wind power, and offshore wind power is 1.182257, 1.294506, and 1.151435, respectively. These are greater than 1 . They are also greater than that of city civil engineering (1.084615), power plants (1.171556), and industrial plants (1.092711) referred to in Table 7. The MCI of mega PV power, onshore wind power, and offshore wind power sources further affects 
other industries as these cover facilities and equipment from other industries. However, the backward linkage effect of the MCI of LNG power is 0.848005 less than 1, because the MCI of LNG thermal is used to cover facilities and equipment within the industry itself and most facilities are imported.

Table 6. Backward linkage effect and forward linkage effect by generation sources.

\begin{tabular}{cccc}
\hline Source & Phase & Backward Linkage Effect & Forward Linkage Effect \\
\hline \multirow{2}{*}{ LNG Thermal } & MCI & 0.848005 & 0.538735 \\
& O\&M & 0.665467 & 2.054125 \\
\hline \multirow{2}{*}{ Small PV } & MCI & 0.843991 & 0.510382 \\
& O\&M & 0.513216 & 2.052864 \\
\hline \multirow{2}{*}{ Mega PV } & MCI & 1.182257 & 0.507629 \\
& O\&M & 0.824770 & 2.052864 \\
\hline \multirow{2}{*}{ Onshore Wind } & MCI & 1.294506 & 0.510961 \\
& O\&M & 0.932346 & 2.052916 \\
\hline \multirow{2}{*}{ Offshore Wind } & MCI & 1.151435 & 0.516083 \\
& O\&M & 0.786679 & 2.055676 \\
\hline
\end{tabular}

Table 7. Backward linkage effect and forward linkage effect by other industries of the 2015 Input-Output table.

\begin{tabular}{cccc}
\hline Classification & Classification (Sector No.) & Backward Linkage Effect & Forward Linkage Effect \\
\hline & Textiles and apparels (No. 11) & 1.073342 & 1.108988 \\
& Semiconductor and related devices (No. 31) & 0.813853 & 0.734365 \\
& Electrical equipment (No. 37) & 1.106721 & 1.422128 \\
Medium-sized & Motor vehicles (No. 40) & 1.369606 & 1.319282 \\
(83 sectors) & Ships (No. 41) & 1.305905 & 0.626747 \\
& Electricity supply (No. 45) & 0.825488 & 1.879492 \\
& Civil engineering (No. 51) & 1.093281 & 0.542595 \\
& Financial services (No. 65) & 0.819409 & 1.669702 \\
Basic-sized & Social care services (No. 78) & 0.871259 & 0.542595 \\
(381 sectors) & Construction of Electricity facility (No. 299) & 1.065020 & 0.523559 \\
& Industrial plant (No. 300) & 1.022010 & 0.523559 \\
\hline
\end{tabular}

Source: Bank of Korea, 2019.

The forward linkage effects are greater in the $\mathrm{O} \& \mathrm{M}$ than the $\mathrm{MCI}$ in all generation sources. The O\&M are heavily influenced by other industries because they operate power facilities to produce electricity and supply it to other industries and the consumer sector as intermediate inputs or final goods. The forward linkage effect for all power sources is greater than 2, which is greater than the average of all industries.

\subsection{Induced Effects}

The analysis results of the induced effects according to the demand of the MCI and O\&M for each power source are presented in Table 8. The amount of demand in this table is the MCI cost and O\&M cost, as shown in Table 3.

Table 9 shows the primary and secondary induced effects. The primary induced effect is the extent to which the production of other industries is affected when the final demand occurs in each power source. The secondary induced effect is that after the final demand occurs in each power source and affects the production of other industries, the employee compensation of the affected industries increases, and this increase stimulates the consumption of the household, resulting in the production of industries. The secondary induced effect is smaller than the primary induced effect because it is associated with the compensation of employees. 
Table 8. Analysis results of induced effects by generation sources. Unit: million won, people.

\begin{tabular}{cccccc}
\hline $\begin{array}{c}\text { Power } \\
\text { Source }\end{array}$ & Phase & Demand & $\begin{array}{c}\text { Induced } \\
\text { Production }\end{array}$ & $\begin{array}{c}\text { Induced } \\
\text { Value-Added }\end{array}$ & $\begin{array}{c}\text { Induced } \\
\text { Employment }\end{array}$ \\
\hline LNG & MCI & 765,900 & $1,475,379$ & 362,501 & 15,910 \\
Thermal & O\&M & 29,916 & 21,194 & 9849 & 232 \\
\hline \multirow{2}{*}{ Small PV } & MCI & 4.500 & 13 & 4 & 0 \\
& O\&M & 0.099 & 0 & 0 & 0 \\
\hline \multirow{2}{*}{ Mega PV } & MCI & 140 & 390 & 108 & 1 \\
& O\&M & 3 & 7 & 3 & 0 \\
Onshore & MCI & 25,000 & 31,234 & 6459 & 212 \\
Wind & O\&M & 475 & 584 & 265 & 2 \\
\hline Offshore & MCI & 600,000 & 807,942 & 232,694 & 7064 \\
Wind & O\&M & 25,272 & 22,910 & 12,466 & 74 \\
\hline
\end{tabular}

Table 9. Primary and secondary induced effect by generation sources. Unit: million won, people

\begin{tabular}{|c|c|c|c|c|c|c|c|}
\hline \multirow{2}{*}{$\begin{array}{l}\text { Power } \\
\text { Source }\end{array}$} & \multirow{2}{*}{ Phase } & \multicolumn{3}{|c|}{ Primary Effects } & \multicolumn{3}{|c|}{ Secondary Effects } \\
\hline & & $\begin{array}{c}\text { Induced } \\
\text { Production }\end{array}$ & $\begin{array}{c}\text { Induced } \\
\text { Value-Added }\end{array}$ & $\begin{array}{c}\text { Induced } \\
\text { Employment }\end{array}$ & $\begin{array}{c}\text { Induced } \\
\text { Production }\end{array}$ & $\begin{array}{c}\text { Induced } \\
\text { Value-Added }\end{array}$ & $\begin{array}{c}\text { Induced } \\
\text { Employment }\end{array}$ \\
\hline LNG & MCI & $1,265,524$ & 280,024 & 14,300 & 209,855 & 82,477 & 1610 \\
\hline Thermal & O\&M & 16,925 & 8168 & 204 & 4269 & 1681 & 28 \\
\hline \multirow{2}{*}{ Small PV } & MCI & 11 & 3 & 0 & 2 & 1 & 0 \\
\hline & O\&M & 0 & 0 & 0 & 0 & 0 & 0 \\
\hline \multirow{2}{*}{ Mega PV } & $\mathrm{MCI}$ & 331 & 85 & 1 & 59 & 23 & 0 \\
\hline & O\&M & 6 & 3 & 0 & 1 & 0 & 0 \\
\hline \multirow{2}{*}{$\begin{array}{l}\text { Onshore } \\
\text { Wind }\end{array}$} & MCI & 27,122 & 4843 & 184 & 4112 & 1616 & 28 \\
\hline & O\&M & 515 & 235 & 2 & 70 & 31 & 0 \\
\hline \multirow{2}{*}{$\begin{array}{l}\text { Offshore } \\
\text { Wind }\end{array}$} & MCI & 680,214 & 182,540 & 3084 & 127,729 & 50,154 & 980 \\
\hline & O\&M & 19,426 & 11,100 & 49 & 3485 & 1366 & 25 \\
\hline
\end{tabular}

As shown in Table 3, the MCI cost and O\&M cost varies depending on generation sources. The MCI cost in all power sources is greater than the O\&M cost. Comparing the induced effect on an amount basis, the inducement effect of the O\&M is inevitably small because of its cost amount. These results can be seen in the case of small PV power, mega $\mathrm{PV}$ power, and onshore wind power. In addition to comparing the induced effect based on cost amount, the induced effect coefficient is derived based on the induced amount and demand amount. The induced-effect coefficients of the MCI and O\&M for each power source are as shown in Table 10.

The induced-effect coefficients of the MCI are greater than those of the O\&M in every power source. The largest induced production effect coefficient is the MCI of mega PV power. The induced production effect coefficient of the MCI is decreased in the order of mega PV $>$ small PV $>$ LNG power $>$ offshore wind $>$ onshore wind. The induced production effect coefficient of the O\&M is decreased in the order of mega $\mathrm{PV}>$ small $\mathrm{PV}>$ onshore wind $>$ offshore wind $>$ LNG thermal.

In the MCI, the induced production effect coefficient of mega PV power is 2.785, which is larger than 2.635 of small PV power. In the O\&M, the induced production effect coefficient of mega PV power is 2.224, which is larger than 2.162 of small PV power. In PV generation, mega PV has a slightly bigger coefficient in the MCI and O\&M than small PV. In wind power, the induced production effect coefficient of the MCI is 1.347 for offshore wind and 1.249 for onshore wind. The induced production effect coefficient for the O\&M is 1.230 for onshore wind and 0.907 for offshore wind. 
Table 10. Induced-effect coefficient by generation sources.

\begin{tabular}{ccccc}
\hline Power Source & Phase & $\begin{array}{c}\text { Induced } \\
\text { Production }\end{array}$ & $\begin{array}{c}\text { Induced } \\
\text { Value Added }\end{array}$ & $\begin{array}{c}\text { Induced Employment } \\
\text { (People/Million Won) }\end{array}$ \\
\hline \multirow{2}{*}{ LNG Thermal } & MCI & 1.926334 & 0.473301 & 0.020773 \\
& O\&M & 0.708450 & 0.329222 & 0.007755 \\
\hline \multirow{2}{*}{ Small PV } & MCI & 2.635208 & 0.768958 & 0.009642 \\
& O\&M & 2.161616 & 0.888889 & 0.003030 \\
\hline \multirow{2}{*}{ Mega PV } & MCI & 2.785279 & 0.769221 & 0.010357 \\
& O\&M & 2.224000 & 0.957667 & 0.006667 \\
\hline \multirow{2}{*}{ Onshore Wind } & MCI & 1.249360 & 0.258360 & 0.008464 \\
& O\&M & 1.230105 & 0.558316 & 0.003789 \\
\hline \multirow{2}{*}{ Offshore Wind } & MCI & 1.346570 & 0.387823 & 0.006773 \\
& O\&M & 0.906537 & 0.493253 & 0.002908 \\
\hline
\end{tabular}

The induced employment coefficient is greater in the MCI than O\&M in all generation sources. LNG thermal has the largest coefficient in the MCI and O\&M. The induced employment coefficient of the MCI is decreased in the order of LNG thermal > mega PV $>$ small PV > onshore wind > offshore wind. The induced employment coefficient of the O\&M is decreased in the order of LNG thermal $>$ mega PV > onshore wind $>$ small PV > offshore wind. In the MCI, the induced employment coefficient of LNG thermal is 0.0208 , which is larger than 0.0104 of mega PV power and 0.0096 of small PV power. In the O\&M, the induced employment coefficient of LNG thermal is 0.0078 , which is larger than 0.0067 of mega PV power and 0.0038 of onshore wind power.

\section{Discussion}

According to the estimation results, the induced-effect coefficients of the $\mathrm{MCI}$ is larger than those of the O\&M in all the power sources mentioned. This result is the same as the result of the Mitsubishi Research Institute (MRI) [8]. In this study, the largest induced production coefficient is the MCI of mega PV power. This is also shown in the O\&M. As the PV power and the wind power have different characteristics, the former has a larger induced coefficient than the latter. In the MCI, PV power is composed of more parts assembly than civil engineering, and wind power accounts for more civil engineering than parts assembly. In the O\&M, PV power is associated with many industries by managing a number of panels, but wind power only manages large-scale blades and towers, so there is little connection between industries.

Although it is the same PV generation, both in the MCI and in O\&M, mega PV power has a greater induced production effect coefficient than that of small PV power. This is because the mega PV power and small PV power have different connections with the other industries. The mega PV power, unlike small PV, requires land construction, larger detection and control facilities and many other equipment. More inputs are needed for management, maintenance, and repair. Offshore wind power is more difficult in civil engineering than onshore wind power. Therefore, more inputs of goods and services, and high technology are needed in the MCI of offshore wind.

The induced employment coefficient is greater in the MCI than O\&M in all generation sources. LNG thermal has a large coefficient in the MCI and O\&M. The MCI of LNG thermal requires the construction of the power plant itself, so the contents of construction are different. The induced employment coefficient of PV power is greater in mega PV power. The induced employment increases along with the scale in PV power. The mega PV power consists of many small PVs, unlike wind power. The induced employment coefficient of wind power is greater on onshore than offshore. This means that the induced employment at a small scale is greater than at a large scale because a certain level of economic efficiency is being realized in wind power. 
According to Matsumoto and Hondo [9], in the case of single-house PV power, the productions of facilities manufacturing, operation and repair are large, but the employment coefficient is small. The production of operation and repair, and employment of wind power are greater than in other renewable energy sources. In the case of Korea, estimation results of the induced production and value-added effects of small PV are not large, and the induced employment effect of small PV is neither small or nor significant compared with other sources. Small PV in Korea has many connections with other industries and labor markets. The induced coefficient of mega PV is similar to or slightly larger than that of small PV. Even large-scale PV power, intermediate inputs and labor inputs are similar to small-scale PV power, and do not decrease significantly. This means that even as PV power grows in size, it does not show much of an efficiency at this moment. Renewable energy is realizing the economic efficiency by expanding like the generation sources with a long history. PV power still has an opportunity to achieve efficiency.

Each country has its own industrial structure. Therefore, just because a certain policy has worked in other countries does not necessarily mean it can be implemented successfully in other countries. For effective policies implemented by one country to be applied in other countries, policies must be customized for each country. The results of this study are applied when predicting the results of implementing policies to expand certain renewable energy sources or LNG power, if a country has an industrial structure and energy facility export and import structure similar to Korea. When countries apply the analysis structure of this study to their own Input-Output table, they can produce results that fit their own conditions. The result of this study will be referred to as a case study in the analysis of other countries.

This analysis does not reflect the supply chain of PV power and wind power in Korea but reflects the statistics of international organizations in 2015 Input-Output statistics of Korea because of data availability. The survey for supply chain information of PV and wind power in Korea will help to estimate the induced effects in Korea more practically.

\section{Conclusions}

The world had a highly dependent energy supply-demand structure on fossil fuels. But gradually, many countries, including Korea, are implementing energy transition policies and declaring carbon neutrality. In Korea's third Energy Basic Plan, Renewable Energy 2030, and the eighth basic plan, the proportions of coal power and nuclear power among the generation mix are decreasing and the proportions of renewable energy and LNG power are increasing. This change in policy direction and generation mix means that future economic activities will take a different appearance than before. This will have a different impact on the economy than before.

Therefore, this study estimated the induced effect of LNG thermal, PV and wind power, which are used as major power sources under Korea's energy transition policy. The $\mathrm{MCI}$ and O\&M of each power source would have different effects, so in the analysis the MCI and O\&M of each power source were distinguished. In addition, the 2015 Input-Output Statistics were used to reflect Korea's economic structure.

PV power has a greater coefficient in induced production and induced value-added than wind power because the $\mathrm{MCI}$ of $\mathrm{PV}$ power has a greater share in component assembly than civil engineering and the MCI of wind power is the opposite. In the O\&M, PV power needs to manage a number of panels, requiring more inputs to manage and repair, which is more relevant between industries and requires more operation personnel. Offshore wind power has a greater induced production effect than onshore wind and PV power due to the large difficulty of civil engineering in the sea. However, O\&M of wind power show less of an inter-industry relationship and less efficiency as scale grows, as the number of blades does not grow proportionally and only a small number of large blades are managed. The MCI of LNG thermal power is different from the MCI of PV power and wind power because the power plant itself must be built. In addition, the induced effect in the MCI and O\&M is small due to the high maturity of the LNG power industry as the generation with 
a long history. However, the induced employment effect in the MCI of LNG power plant is greater than renewable energy because of the construction of power plants.

The carbon neutrality and energy transition policies implemented by Korea have a certain level of inducement effect and offset the burden of transition costs even if existing power sources are replaced with environmentally friendly power sources. The efficiency of existing power generation sources, such as LNG power, is appearing on wind power and is gradually implemented in PV power. This increases the likelihood of achieving two simultaneous objectives of continuing production activities on the economic side while responding to climate change on the environmental side.

Author Contributions: Methodology, scenario design, and simulation, Y.-K.K.; evaluation and verification, J.-W.K. and Y.-K.K.; writing-original draft preparation, Y.-K.K.; writing-review and editing, J.-W.K.; supervision, Y.-K.K. Both authors have read and agreed to the published version of the manuscript.

Funding: This research received no external funding.

Institutional Review Board Statement: Not applicable.

Informed Consent Statement: Not applicable.

Data Availability Statement: The data in this study are available from the corresponding author on reasonable request.

Acknowledgments: This research was supported by the Basic Research Project (GP2021-005) of the Korea Institute of Geoscience and Mineral Resources (KIGAM), funded by the Ministry of Science and ICT.

Conflicts of Interest: The authors declare no conflict of interest.

\section{References}

1. Smil, V. Examining energy transitions: A dozen insights based on performance. Energy Res. Soc. Sci. 2016, 22, 194-197. [CrossRef]

2. International Renewable Energy Agency (IRENA). Global Renewable Outlook 2020; IRENA: Abu Dhabi, United Arab Emirates, December 2020; Available online: https:/ / www.irena.org/publications/2020/Apr/Global-Renewables-Outlook-2020 (accessed on 3 August 2020).

3. Ministry of Trade, Industry and Energy Korea (MOTIE). Transition to Safe and Clear Energy, Policy Briefing. 2019. Available online: http:/ / www.motie.go.kr/motie/py/brf/motiebriefing/motiebriefing402.do?brf_code_v=402\#header (accessed on 27 December 2020).

4. Cho, S.-J.; Kim, Y.K. Tax Reform for the Energy Transition in Korea's Power Generation Sector. Energies 2020, 13, 5233. [CrossRef]

5. Ministry of Trade, Industry and Energy of Korea (MOTIE). The Eighth Electricity Supply-Demand Basic Plan (2017-2031). 2017. Available online: https:/ /www.motie.go.kr/motie/ms/nt/announce3/bbs/bbsView.do?bbs_seq_n=64603\&bbs_cd_n=6 (accessed on 29 December 2017).

6. International Renewable Energy Agency (IRENA). Renewable Power Generation Costs in 2017; IRENA: Abu Dhabi, United Arab Emirates, 2018; Available online: https:/ / www.irena.org/publicaitons/2018/Jan/Renewable-power-generaiton-costs-in-2017 (accessed on 24 July 2020).

7. Republic of Korea. Energy Transition Policy, Policy Briefing. 2020. Available online: https://www.korea.kr/special/ policyCurationView.do?newsId=148864795 (accessed on 27 December 2020).

8. Mitsubishi Research Institute (MRI). Medium and Long-Term Introduction of Renewable Energy toward the Low-Carbon Society at Heisei 27; Ministry of Environment Japan (MOE): Tokyo, Japan, 2016.

9. Matsumoto, N.; Hondo, H. Analysis on Employment Effects of the Introduction of Renewable Energy Technologies Using an Extended Input-output Table. J. Jpn. Inst. Energy 2011, 90, 258-267. [CrossRef]

10. International Renewable Energy Agency (IRENA). Renewable Energy and Jobs; IRENA: Abu Dhabi, United Arab Emirates, December 2016.

11. Baba, K. Energy Environment Strategy Research of Heisei 23-Economic and Employment Effect of Energy; Report 2012; Nomura Research Institute: Tokyo, Japan, 2012.

12. Mah, D.N.-Y.; Cheung, D.M.-W. Conceptualizing Niche-Regime Dynamics of Energy Transitions from a Political Economic Perspective: Insights from Community-Led Urban Solar in Seoul. Sustainability 2020, 12, 4818. [CrossRef]

13. Bank of Korea. 2015 Input-Output Statistics; Bank of Korea: Seoul, Korea, 2019; ISSN 1226-606X.

14. Korea Energy Economics Institute (KEEI). Estimation of Levelized Cost of Electricity (LCOE) of Energy Sources; Ministry of Trade, Industry and Energy Korea (MOTIE): Ulsan, Korea, 2017; pp. 41-42.

15. Bank of Korea. Guideline for Input-Output Analysis; Bank of Korea: Seoul, Korea, 2014. 
16. Kim, Y.K.; Kim, J.-I. Forecast of Domestic Outputs from the Introduction of Hydrogen Energy in Korea Using Input-Output Analysis. New Renew. Energy 2016, 2, 72-81.

17. Economic Research Institute Japan Society for the Promotion of Machine Industry (JSPMI). Research on Early Understanding of Industrial Structure (1). Report. 2000. Available online: http:/ /www.jspmi.or.jp/system/1_cont.php?ctid=1202\&rid=401 (accessed on 23 March 2021).

18. Korea Electric Power Corporation (KEPCO); Management Research Institute. Report for National Economic Effect Analysis Model Development of Electricity Industry's Export; Ministry of Knowledge Economy Korea (MIKE): Seoul, Korea, 2012 ; p. 51.

19. Mitsubishi Research Institute (MRI). Study toward Long-Term Stabilization and Independence of Renewable Energy; Ministry of Economy, Trade and Industry Japan (METI): Tokyo, Japan, 2016.

20. Mitsubishi Research Institute (MRI). Medium and Long-Term Introduction of Renewable Energy toward the Low-Carbon Society at Heisei 28; Ministry of Environment Japan (MOE): Tokyo, Japan, 2017.

21. Nakamura, R.; Ishikawa, Y.; Matsumoto, A. Economic Effect of Renewable Energy Inducement in Tohoku Province-Analysis for Inducement of Photovoltaic Generation and Wind Generation Using Regional Input-Output Table; RIETI Policy Discussion Paper Series 12-P-014; RIETI: Tokyo, Japan, 2012.

22. Science and Technology Foresight Center; National Institute of Science and Technology Policy (NISTEP); Ministry of Education, Culture, Sports, Science and Technology Japan (MEXT). Economic and Environmental Impact Analysis for Construction of Renewable Energy Power Plants by Extended Input-Output Table; Discussion Paper No.96; MEXT: Tokyo, Japan, 2013.

23. Repartners, Category: Solar Power. Available online: www.repartners.org/category/solar-power (accessed on 27 December 2020).

24. Korea Power Exchange (KPX). Capacity and Generation by Type Data of Electric Power Statistics Information System (EPSIS). Available online: http:/ / epsis.kpx.or.kr/epsisnew/selectEkpoBgtChart.do?menuId=020200 (accessed on 3 August 2020).

25. Korea Energy Economics Institute (KEEI). 2015 Yearbook of Energy Statistics; Korea Energy Economics Institute (KEEI): Ulsan, Korea, 2016.

26. Korea Electric Power Corporation (KEPCO). Statistics of Electric Power in Korea 2015; Korea Electric Power Corporation (KEPCO): Naju, Korea, 2016.

27. Ministry of Science and ICT Korea (MSIT). Survey on the Status of Nuclear Industries in 2015; Report; Ministry of Science and ICT Korea (MSIT): Sejong, Korea, 2016.

28. International Renewable Energy Agency (IRENA). Renewable Energy and Jobs; IRENA: Abu Dhabi, United Arab Emirates, 2013. 